\title{
Influence of different complexity levels of road traffic models on air quality modelling at street scale
}

\author{
Bruno Vicente ${ }^{1}$, Sandra Rafael ${ }^{1 *}$, Vera Rodrigues ${ }^{1}$, Hélder Relvas $^{1}$, Mariana Vilaça $^{2}$, João \\ Teixeira $^{2}$, Jorge Bandeira ${ }^{2}$, Margarida Coelho ${ }^{2}$, Carlos Borrego ${ }^{1}$ \\ ${ }^{1}$ CESAM, Department of Environment and Planning, University of Aveiro, 3810-193 Aveiro, \\ Portugal \\ ${ }^{2}$ TEMA, Department of Mechanical Engineering, University of Aveiro, 3810-193 Aveiro, Portugal \\ *Corresponding author: sandra.rafael@ua.pt
}

\section{Abstract}

Urban mobility accounts for $38 \%$ and $19 \%$ of nitrogen oxide (NOx) and particulate matter (PM) emissions at European urban areas, respectively. Despite of all the technological development around automobile industry, urban areas are still facing problems related to exposure to high levels of air pollutants. Increase the accuracy of both emissions and air quality modelling from road traffic is a key-issue for the management of air pollution in road transport sector. This study assessed the influence of using different road traffic emission models on the accuracy of air quality modelling with street level resolution, having as case study an urban area located on the centre region of Portugal. Two emission models, with different complexity levels regarding the ability to characterize the traffic dynamics were analysed, namely, TREM (Transport Emission Model for Line Sources) and VSP (Vehicle Specific Power), based on data obtained in an experimental campaign. To perform the air quality simulations the VADIS (pollutant DISpersion in the atmosphere under VAriable wind conditions) model was used and two pollutants were analysed: NOx and PM10. The results showed that the magnitude of PM10 and NOx concentrations were result of a conjoint influence of traffic dynamics and meteorological conditions. Comparison between measured and modelled data showed that the VADIS model could track the evolution of NOx levels, for both emission models considered, displaying a high correlation $(>0.8)$ between traffic-related NOx emissions and NOx concentrations. For PM10, VADIS model is more sensitive to the differences in the emissions calculation; however, it was observed that the traffic-related PM10 emissions accounts $1.3-8.4 \%$ to the PM10 concentration levels at the study area.

Keywords: CFD modelling, experimental campaign, emissions modelling, street air quality, road traffic

\section{Introduction}

In the European Union (EU) $72 \%$ of the population lives in urban areas, i.e. $42 \%$ in cities and $30 \%$ in towns and suburban areas (Eurostat, 2015, EEA, 2016a). These numbers show a high demand on transport needs in urban areas; the tendency shows that transport needs tend to grow, increasing the pressure in this sector. Emissions due to road traffic sector are known to make a large contribution to air pollution on urban areas, especially to the particulate matter with an aerodynamic diameter less than or equal to $10 \mu \mathrm{m}$ (PM10) and nitrogen oxides (NOx) concentrations (Masiol et al., 2012; Rissler et al., 2012; Pant and Harrison, 2013). In recent years, air quality patterns in Europe have improved due to the implementation of effective policies and 
actions to reduce air pollutants emissions. At the transport sector a set control measures of roadtraffic emissions was implemented, such as the introduction of Euro emission standards and consequently the installation of catalytic converters and diesel particulate filters in vehicles, have decreased total emissions of NOx, PM and carbon monoxide (CO) from road transport (EEA, 2015a). In fact, these reductions were more significant in CO emissions (70\% between 2000 and 2013). Additionally, the introduction of fuel quality standards, namely limiting sulphur and banning lead, contributed to a decrease of emissions, such as sulphur oxides (SOx) (EEA, 2015a).

Despite of that, in 2014, passenger cars emissions of NOx increased by $3.3 \%$ (EU-28) due to an increase of transport activity and an increase in the number of diesel cars in Europe, being the first annual increase since 1990 (EEA, 2016b). Currently, up to 30\% of European citizens living in cities are still exposed to air pollution levels exceeding European Union air quality standards (EEA, 2014, 2015b). According with the European Environment Agency (EEA), in the EU-28, in 2013, the exposure levels has been estimated as causing 436k deaths due to PM2.5 (particulate matter with an aerodynamic diameter less than or equal to $2.5 \mu \mathrm{m}$ ) exposure, $68 \mathrm{k}$ due to $\mathrm{NO}_{2}$ exposure and 16k due to $\mathrm{O}_{3}$ exposure, per year (EEA, 2016a). In Portugal, the impacts of road traffic emissions on air quality are mostly noticeable in high and medium-sized urban areas. Air Quality Plans (AQP) have been developed for these areas since 2001 for PM10 and $\mathrm{NO}_{2}$, and more recently for ozone $\left(\mathrm{O}_{3}\right)$ (Miranda et al., 2015). Despite some improvements on air quality levels after the AQP implementation, recent data still indicate exceedances to the legal limit values, thus assessment of PM10 and $\mathrm{NO}_{2}$ concentrations at local scale is still required. Air pollution is still a current issue alarmingly threatening human health and well-being in urban areas (Costa et al., 2016).

Computational Fluid Dynamics (CFD) methods became widely used on air quality studies at local scale due to their capability to deal with complex structure of air flows and turbulence (Tominaga \& Stathopoulos, 2013; Lateb et al., 2015). Despite the complexity behind the development of these models, the accuracy and precision of their results are often low and usually associated with the emission inventories used as input in those models (Taghavi et al., 2005). Urban emission inventories with higher temporal and spatial resolution are needed for several applications, such as urban air pollution modelling, population exposure modelling, definition of sustainable urban development policies, etc. In the case of road traffic, the most commonly used technique to quantify the emissions is based on the principle that the average emission factor for a certain pollutant and a given type of vehicles vary according to the average speed during a trip (Thunis et al., 2016). For urban applications, hourly emissions for each road link are usually required. Uncertainty of these data, as well as uncertainty associated with the resulting emissions, is an important scope of research. Atmospheric emission inventories are usually quantified using one of the two approaches: i) top-down, based on the disaggregation process of total emissions from a certain area to smaller administrative units or a regular grid with higher resolution (Eicker et al., 2008); and ii) bottom-up, based on emission estimation using detailed data of each emission source. The top-down approach is very useful when local detailed information about the emissions of different activity sectors are scarce (Palacios et al., 2001). A study conducted by Coelho et al. (2014) have used a combination of different road traffic emissions models based on a bottom-up and a top-down approach to assess if the outputs of an air quality model can be improved in a regional level. The study concluded that the bottom-up approach would be most suitable used at an urban level, when PM10 concentrations are a major concern (in terms of exceeding the air quality standards established for this pollutant). The availability of input data in terms of quantity and quality is pointed as a relevant issue when the bottom-up approach is applied.

The use of Computational Fluid Dynamics (CFD) models allied with the inclusion of reliable emissions for road-traffic are preponderant to define and evaluate the impacts of different measures and scenarios to enhance air quality at urban areas. The aim of the presented work is to characterize the air quality of a typical medium-size city and to compare the influence of 
different traffic emission models, based on the bottom-up emission approach, in the performance of the CFD model VADIS. For that, two different pollutants were considered, the PM10 and NOx. A neighborhood area located in Aveiro city (centre region of Portugal) was considered as case study, which is characterized by a high traffic intensity. This work is distinguishable from previous air quality studies conducted at the same region, due to the applied methodology that provides an accurate and highly spatially resolved road traffic emission (by means of real measured traffic data) and air quality data (at street scale). This feature allied to the evaluation of how different complexity levels of road traffic emission data influence air quality model performance (given an outlook regarding the uncertainties) at street level is quite novel. This work is a multidisciplinary study that addresses different components of the atmosphere and its linkages with the anthroposphere. Highly spatial data have been identified as a key component of a decisionsupport tool for the analysis and evaluation of a variety of air quality and climate change policies, which linked to the need of accomplish the sustainable development goal of make cities sustainable and resilient, shows the pertinence and relevance of the followed work.

The paper is structured as followed: section 2 describes the case study and the modelling setup methodology, including a brief description of the applied models and their configuration for the simulations. The air quality status of the study area is characterized in section 3 . A comparative analysis of the emission models approaches and its influence on the accuracy of the air quality model results is also presented in section 3. Conclusions follow in section 4.

\section{Data and Method}

\subsection{Case study description}

A main avenue of the city of Aveiro, a medium-size city in Northwest Portugal, called Avenida 25 de Abril (Fig. 1) was selected as case study. This avenue is located near the city centre, surrounded by residential buildings (building blocks of similar height) and two schools. The case study is located in one of the most important thoroughfares of the city (responsible for the majority of the road traffic emission of the neighbourhood - around $80 \%$ ) which crosses several secondary roads (with low road traffic volume). An Air Quality Station (AQS), classified as urban traffic according to the type of emission source, is built-in in the middle of the avenue. The AQS is monitoring the concentration of multiple pollutants, which makes the case study an ideal case, since allows a comparison between the CFD model results and the real-world measurements.

Several studies have been performed through the years in this area. The most recently, performed by Valente et al. (2014), assessed the individual exposure of a set of student's to carbon monoxide concentrations, inside the classrooms, related to road traffic emissions. This study shows, through a local scale computational approach, that the individual exposure of pedestrians in an urban area is extremely spatially dependent, as a consequence of the wind flow and air pollutant dispersion patterns and characteristics. Also, their exposure in the indoors varies along with the outdoor concentration's. These results reinforce the need to perform studies on outdoor air quality, particularly in urban areas where schools and hospitals take place and where susceptible population groups spend a high amount of time, focused on road traffic as emission source. Guarantee the accuracy of these emission estimations, at local scale, is crucial to reduce the errors related to numerical models application. This will enable, for example, the assessment of urban planning options to enhance air quality and to reduce population exposure. 


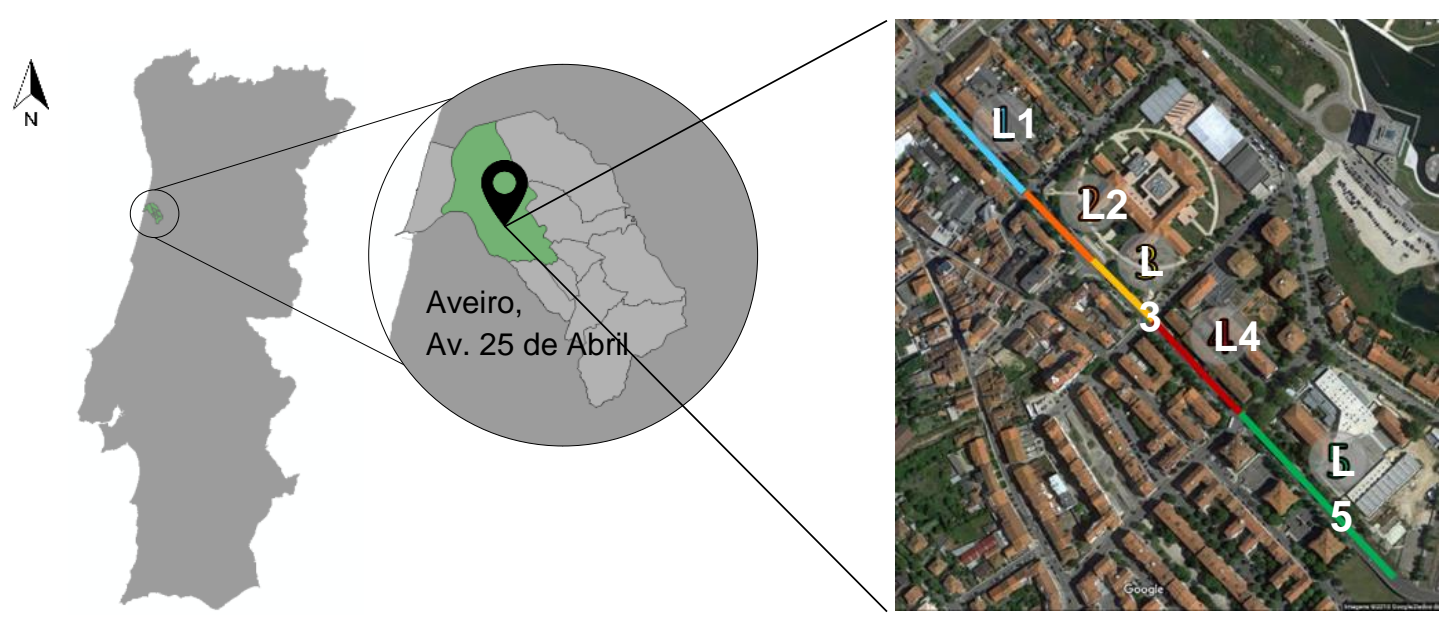

Fig. 1. Geographical location of Aveiro, Avenida 25 de Abril: Centre region of Portugal. Avenida 25 de Abril is located in the centre region of mainland Portugal, in the municipality of Aveiro at $40^{\circ} 38^{\prime} 14.9^{\prime \prime} \mathrm{N} 8^{\circ} 38^{\prime} 54.5^{\prime \prime} \mathrm{W}$ (Google earth V10, SIO, NOAA, United States Navy, NGA, GEBCO, Image Landset, Image IBCAO, http://www.earth.google.com [November 20, 2017]). Five link numbers (left image) highlights the Avenida 25 de Abril length. Each link is identified with a distinct colour: L1 with a blue colour, L2 with an orange colour, L3 with a yellow colour, L4 with a red colour and L5 with a green colour.

To accomplish the purposed goal, an experimental campaign (on $7^{\text {th }}$ of February 2017) was performed in this avenue to characterize the traffic flow (speed, time and distance) and to count the number of vehicles which use this road in an hourly basis. This data was used as an input for the traffic emissions models (see section 2.2.1). Fig. 2a characterizes the meteorological conditions (wind velocity and wind direction) for the experimental campaign day, measured in a meteorological station located closed to the study area.

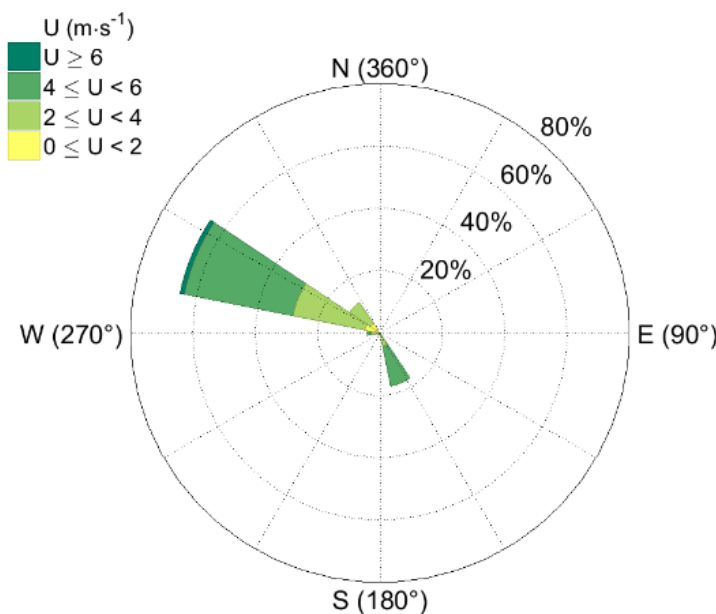

(a)

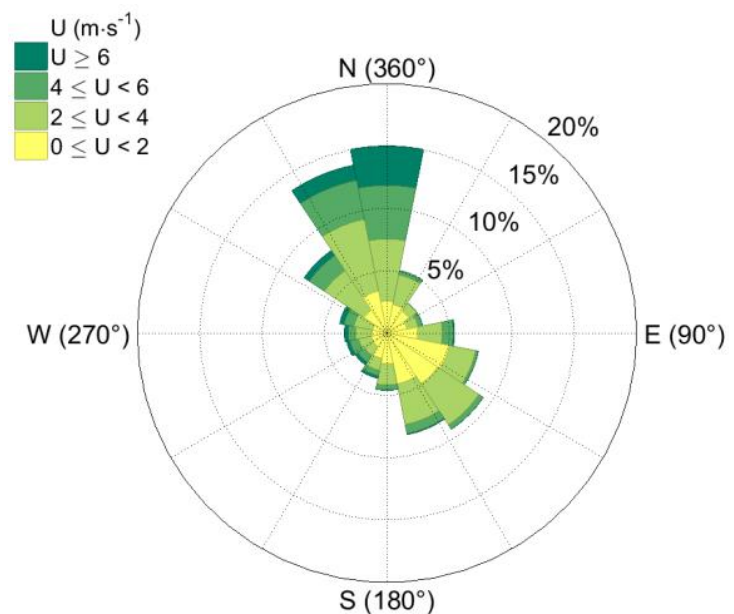

(b)

Fig. 2. a) Wind rose with meteorological data for $7^{\text {th }}$ of February of 2017. b) Wind rose obtained from the meteorological measured data at the station located near the study area, for the period between 2012 and 2016.

The wind velocity and direction values were acquired at $10 \mathrm{~m}$ high, by a meteorological station which is located nearby the computational domain. These data describe the average hourly wind flow conditions that were used as inflow boundary conditions for the simulations (see section 2.2). 
It can be observed that the wind direction was approximately constant from west-northwest (WNW) (Fig. 2a), indicating that the main street canyon is in line with the incoming flow. Noteworthy oscillations in the wind velocity were observed during the study period, with a maximum variation between 2 and $6 \mathrm{~m} \cdot \mathrm{s}^{-1}$. The data acquired on the last five-years (2012-2016) in the meteorological station were also analysed (Fig. 2b), showing that the wind blows from the north-westerly quadrant with a frequency of more than $40 \%$, with the majority of the wind speed comprised in a range of $2-6 \mathrm{~m} \cdot \mathrm{s}^{-1}$. The period of the experimental campaign is therefore representative of the typical meteorological conditions of the study area, corresponding also to neutral stability conditions, in agreement with the numerical approach adopted in this study.

\subsection{Modelling setup}

\subsubsection{Emission approaches}

The experimental campaign was performed with the application of emissions models based on a bottom-up approaches. For vehicle dynamic monitoring three different light-duty vehicles (Table 1) were equipped with Global Navigation Satellite System (GNSS) data loggers to collect secondby-second trajectory data and covering a total of $128 \mathrm{~km}$ and 160 runs in each direction. For traffic flow monitoring, two static video cameras were used, one located at the beginning and another located at the end of the road segment.

Table 1. Data Collection Vehicles Characterization.

\begin{tabular}{ccccc}
\hline Vehicle Name & Type of fuel & Year & Engine Size (L) & Horsepower \\
\hline Opel Astra & Gasoline & 2006 & 1.3 & 90 \\
Renault Scenic & Gasoline & 2004 & 1.5 & 100 \\
Toyota Yaris & Diesel & 2016 & 1.0 & 75 \\
\hline
\end{tabular}

The avenue with $0.7 \mathrm{~km}$ was divided in five different links based on the intersections connections (Fig. 1) and the total emissions were calculated for each link. Two intersections are controlled by traffic lights. Hourly averaged PM10 and NOx emissions for the main avenue of the study area were estimated by applying the Vehicle Specific Power (VSP) model and the Transport Emission Model for Line Sources (TREM).

\section{VSP}

The VSP model is based on vehicle specific power concept for estimating vehicular emissions (USEPA, 2002). This model represents the sum of the loads resulting from aerodynamic drag, acceleration, rolling resistance, and road grade, all divided by the mass of the vehicle (Palacios, 1999). VSP values are categorized in 14 modes. Modes 1 and 2 represents deceleration modes, mode 3 includes the idle mode, while VSP modes 4 to 14 represent combinations of positive accelerations and growing speeds. Equation (1) provides the VSP calculation for passenger vehicle (USEPA, 2002). Then for each mode a specific emission factor is assigned to estimate NOx and PM emissions.

$V S P=v \times[1.1 \times a+9.81 \times \sin (\arctan ($ grade $))+0.132]+0.00032 \times v^{3}$

where VSP is the Vehicle Specific Power $\left(\mathrm{kW} \cdot \mathrm{ton}^{-1}\right), v$ is the vehicle instantaneous speed $\left(\mathrm{m} \cdot \mathrm{s}^{-1}\right)$, $a$ is the vehicle instantaneous acceleration or deceleration $\left(\mathrm{m}^{\left.-\mathrm{s}^{-2}\right)}\right.$ and the grade is the terrain 
gradient (decimal fraction). The VSP methodology was applied based on the national fleet sample based on COPERT software (Computer Programme to calculate Emissions from Road Transport) related with national fleet $\left(23 \%\right.$ - diesel vehicle with more than $2500 \mathrm{~cm}^{3}, 34 \%$ - diesel vehicle until $1900 \mathrm{~cm}^{3}, 36 \%$ - gasoline vehicle until $1400 \mathrm{~cm}^{3}, 6 \%$ - gasoline vehicle until $1800 \mathrm{~cm}^{3}$, and $0,6 \%$ gasoline vehicles with more than $2000 \mathrm{~cm}^{3}$ ) (Emisia SA, 2017).

\section{TREM}

TREM was firstly developed on the basis of COST319/MEET approach and focused on CO, NOx, Volatile Organic Compounds including methane, carbon dioxide, sulphur dioxide and PM10 (Borrego et al. 2000, 2003, 2004; Tchepel et al., 2012). The prime objective of TREM is the estimation of road traffic emissions with high temporal and spatial resolution to be used in air quality modelling. Although the average-speed approach for the emission factors implemented in the model follows the European guidelines (EMEP/EEA 2010) the way how transport activity data are considered for the emission inventorying is conceptually different. Roads are considered as line sources and emissions induced by vehicles are estimated individually for each road segment considering detailed information on traffic flow, in this case, obtained in the experimental campaign.

The emission of the pollutant $p(E p[g])$ for each road segment is estimated by the model as following:

$$
E_{p}=\sum\left(e_{i p}(v) \cdot N_{i}\right) \cdot L
$$

where: $e_{i p}(v)$ is the emission factor $\left(\mathrm{g} \cdot \mathrm{km}^{-1}\right)$ for pollutant $p$ and vehicle class $i$ defined as a function of average speed $v\left(\mathrm{~km} \cdot \mathrm{h}^{-1}\right) ; N_{i}$ is the number of vehicles of class $i$ and $L$ is the road segment length $(\mathrm{km})$. The emission factors were derived from the average speed (approximately $30 \mathrm{~km} \cdot \mathrm{h}$ 1 in the considered road), fuel type (gasoline, diesel and liquefied petroleum gas), engine capacity and emission technology (emission standards implementation associated to vehicle age). Different vehicles categories are taking into account by TREM: passenger cars, light duty vehicles, heavy duty vehicles and urban buses. The national vehicle fleet composition was obtained from the COPERT database. Also, and since the TREM model needs a detailed discretization regarding the vehicle categories (a total of 350 classes are considered in the model), national and regional statistical information were used for this purpose (ACAP, 2015).

Fig. 3 shows the histogram of time spent under different speed ranges. It should be highlighted the high percentage of time spent in stop and go situations $\left(0-5 \mathrm{~km} \cdot \mathrm{h}^{-1}\right)$ and a high variability of the time spent operating on the remaining speed bins. The main difference between VSP and TREM methodologies is related to vehicle speed. VSP considers the instantaneous speed and acceleration, allowing the characterization of vehicles dynamics, particularly important in the case study, due to presence of traffic lights and the existence of pick up and drop off points related to the schools. TREM considers the average speed, and so, reflects a homogeneous vehicle behaviour, which implies a limited capacity to reflect traffic behaviour and speed variations in an urban arterial. On the other hand emissions factors for VSP estimations are based on a limited number of vehicles' categories, which represents a limitation in terms of the representativeness of local fleet characteristics, whereas TREM model emissions factors arise from the linkages between four categories of data sub-divided according to the fuel used, and by engine size, weight or technology level of the vehicle, allowing a higher degree of detail in the characterization of fleet composition. These distinct methods will be traduced in different levels of emission estimation accuracy. 


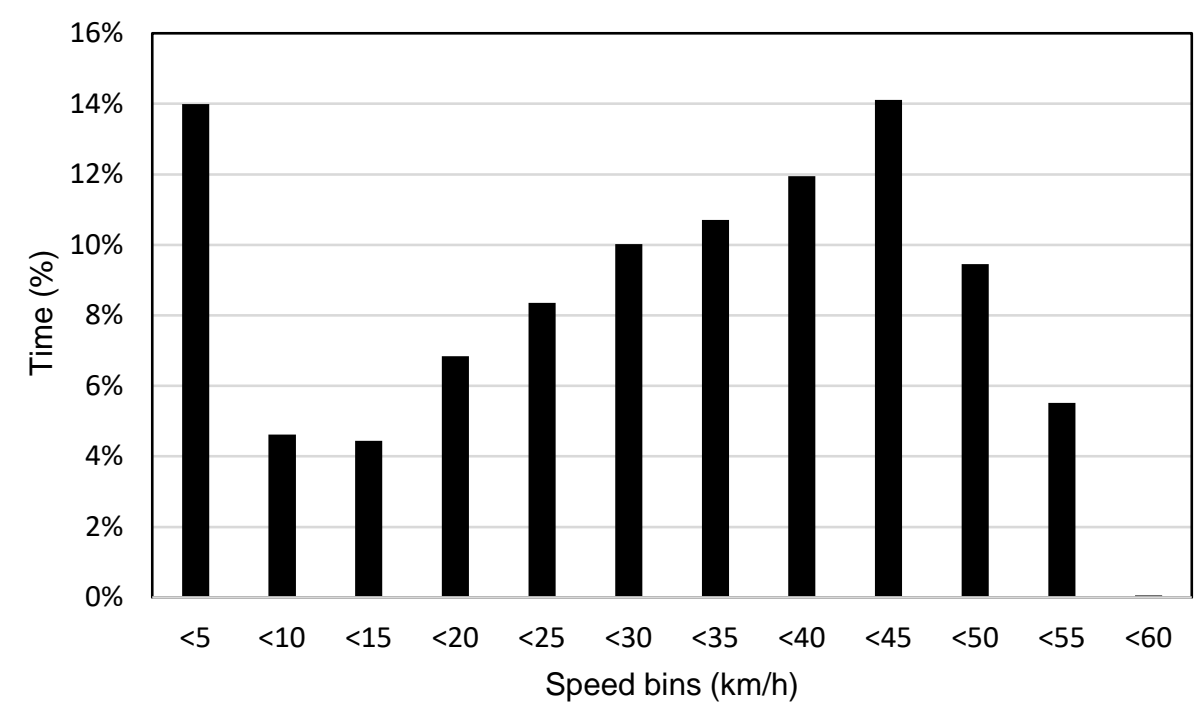

Fig. 3. Histogram of Speed data frequency (relative time spent over different speed bins).

\subsubsection{Air quality modelling}

The CFD model VADIS (pollutant DISpersion in the atmosphere under VAriable wind conditions) was applied to the case study to assess local scale air pollutants dispersion. VADIS performance has been improved through the years, based on the comparison of modelled data with wind tunnel measurements and data from air quality stations (Borrego et al., 2003, 2004; Richards et al., 2006; Amorim et al., 2013; Rodrigues et al., 2018; Rafael et al., 2018). Currently, VADIS has the capability to support multi-obstacle (e.g. buildings and trees) and multi-source description as well as, time varying flow fields and time varying emissions, allowing the evaluation of maximum shortterm local concentrations in urban geometries (Amorim et al., 2013).

The VADIS structure is based on a bi-modular approach: the FLOW and the DISPER modules (Fig. 4). The FLOW module uses the numerical solution of the three-dimensional (3D) Reynolds averaged Navier-Stokes equations applying the $k-\varepsilon$ turbulence closure scheme to calculate the wind, turbulent viscosity, pressure, turbulence kinetic energy and temperature 3D fields. In this module two different grids are used: the wind and the cartographic grids. The information related to the obstacles (buildings or vegetation) and to the emission sources position (e.g. roads) and dimensions is defined on the cartographic grid. The wind field is calculated over an Eulerian Cartesian 3D grid, which is overlaid to the cartographic one and rotates according to the wind direction. The grids dimensions and number of cells in each axis must be defined as a compromise between the required resolution, accuracy and the computational demand. The DISPER module applies the Lagrangian approach to the computation of the 3D pollutant concentration field using the wind field previously estimated by the FLOW. The Lagrangian approach assumes that the spatial and temporal dispersion of the mass of pollutant emitted is represented by a large number of numerical particles arbitrarily released in the flow. In each time step, each particle displacement is calculated by the sum of a deterministic component obtained from the velocity field, the stochastic component related with the local turbulence translated by the Langevin stochastic theory and the influence of the fluctuation forces, represent by the Langevin equation (Lee and Naesslund, 1998). Initially, the wind field is calculated considering the stationary conditions (FLOW module) and then the model calculated the displacement of these numerical particles over the cartographic grid (DISPER module). Integrated in the DISPER module, the Urban Vegetation (URVE) module, accounts for the aerodynamic effects of trees over 
the 3D wind field. Consequently, the dispersion of the emitted air pollutants is conditioned by vegetation through this disturbed wind flow, allowing a better understanding of the flow and dispersion of air pollutants in urban environments. The magnitude of this perturbation depends most of all on the characteristics of the vegetation itself (e.g., location, size) and of the incoming air flow (e.g., velocity, direction, turbulence).

The output provided by VADIS includes the three wind velocity components, the turbulent viscosity, the turbulent kinetic energy, the turbulent dissipation and the pollutant concentration in each grid cell for the entire cartographic grid. A more complete description of VADIS can be found on Borrego et al. $(2003,2004)$ and Amorim et al. $(2013)$.

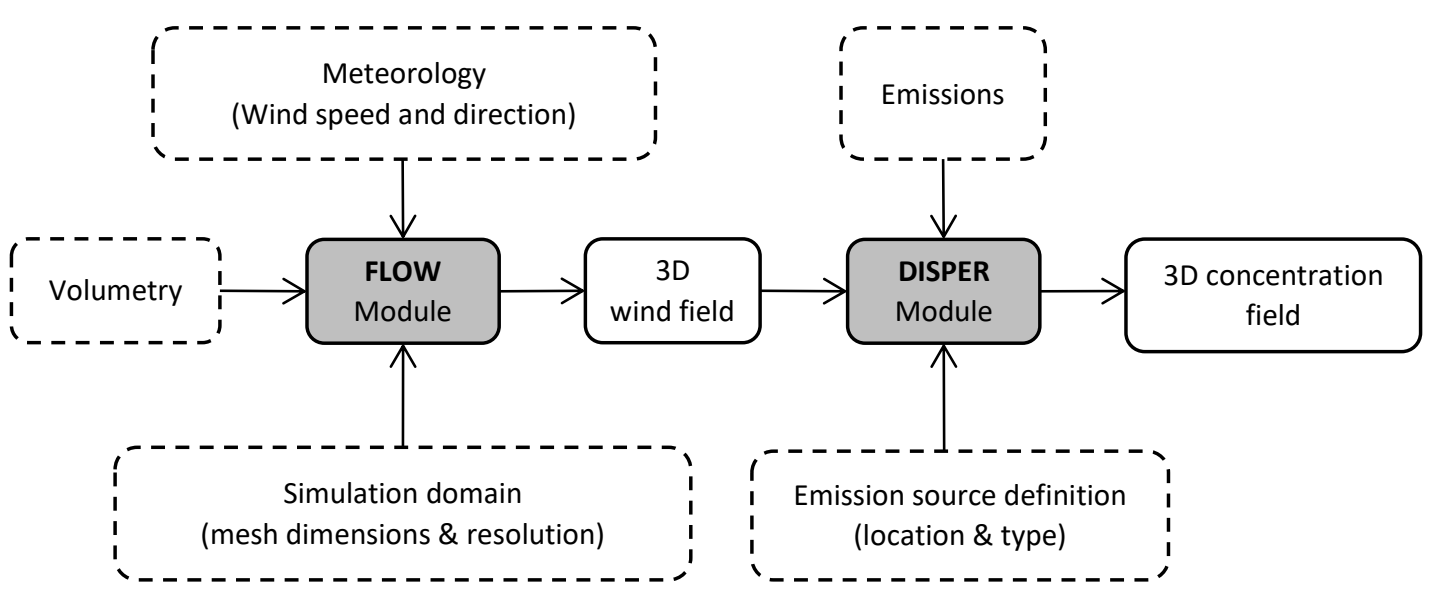

Fig. 4. Representative scheme of VADIS model.

\section{Computational domain}

The computational domain was designed following the guidelines proposed by COST Action 732 (Frank et al., 2007). Thus, for the simulation of urban flows with multiple buildings, the vertical, lateral and downwind extensions of the computational domain were defined with a minimum of $5 \mathrm{H}_{\max }$, where $\mathrm{H}_{\max }$ represents the height of the tallest building. The CFD simulations were performed for a domain of $1248 \times 1248 \times 120 \mathrm{~m}^{3}(\mathrm{~L} \times \mathrm{W} \times \mathrm{H})$, with a grid resolution of $3 \times 3 \times 3$ $\mathrm{m}^{3}$, which totalize a number of 6922240 cells. The domain obstacles (urban design) was characterized according to a geographic information system (GIS), which allows the creation of a virtual configuration of the study area, and so, considering the influence of artificial and natural structures (buildings and trees) to the flow dynamics. The complexity of the urban objects (buildings and trees) within the computational domain was simplified by assembling adjacent individual volumes with similar characteristics. Specifically in the case of trees, the grouped elements were defined as parallelepipeds positioned at a given distance above ground, representing the average trunk height. The generation of the urban objects (3D buildings, trees and roads) have been virtually defined in VADIS using the geometry pre-processors developed, based on the coordinates of the objects (Fig. 5). This case study complies a total number of 297 buildings with a height which varies between 3 and $24 \mathrm{~m}$, and a number of 310 trees with a height varying between $3 \mathrm{~m}$ and $15 \mathrm{~m}$ (total height).

Inflow boundary conditions for the horizontal wind velocity components, $u$ and v, were prescribed based on the meteorological data presented in section 2.1. Richards and Hoxey's (1993) vertical profile equations were used to specify the variation of velocity $(U), k$ and $\varepsilon$ with height at the inlet boundaries assuming neutral stability conditions. The remaining boundary conditions (upper, lower and wall boundaries, as well as tree boundaries conditions) were defined following the guidelines indicated by Amorim et al. (2013). 

for both emission models were carried out, in a total of 144 simulations.
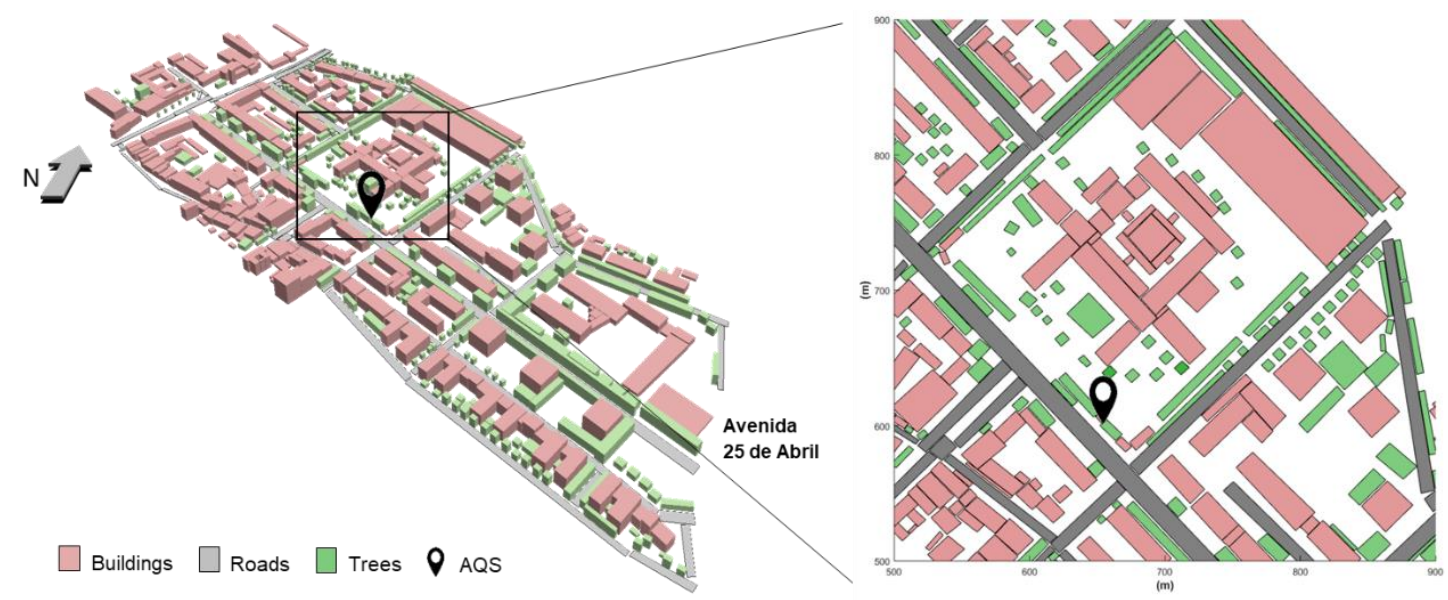

Fig. 5. Computational domain considered for CFD simulations - Avenida 25 de Abril in Aveiro, Portugal. The pink polygons represent the buildings, the green ones represent the trees, and the grey polygons represent the roads. The black icon shows the location of the Air Quality Station.

\subsection{Air quality measured data}

Aiming to characterize the daily profile of NOx and PM10 concentrations and to assess the accuracy of numerical simulations for the period of the experimental campaign, a monitoring network consisting of two stations (an urban traffic station and a suburban background station) was designed. Both stations belong to the national network QUALAR (http://www.qualar.org), managed by the Portuguese Environmental Agency (APA). Air quality monitoring equipment with similar technical specifications is used in both stations. The urban traffic [Urb.] station is located within the study domain and so its concentrations are determined predominantly by the emissions from nearby traffic. Data from a suburban background station [Back.], located southwest from the study area at approximately $6.5 \mathrm{~km}$, was included in the analysis. This station allows a characterization of the concentrations levels that are not considerably influenced by single (local) sources but by an integrated contribution from all sources. However, background concentration are not a fixed value and vary in that it may be influenced by regional air quality and indirectly by local sources, i.e. background concentration is likely to increase in response to peak traffic emissions or decrease at night in response to minimal traffic emissions (Moreno et al., 2009).

\section{Results and Discussion}

Given the described methodology (section 2), the air quality status of the study area was characterized, both in terms of road traffic emissions (section 3.1.1) and air quality, including the assessment of the wind flow pattern and air pollutants concentration (section 3.1.2). Afterwards, the influence of different emission approaches to the accuracy of VADIS performance was evaluated (section 3.2), through a statistical analysis and evaluation of the temporal profiles.

\subsection{Air quality status of study area}

\subsubsection{Road traffic emissions}


Based on the two emission models previously described, the hourly road traffic emissions were estimated for the experimental campaign period conducted in the study area. Fig. 6 shows the obtained results for both analysed pollutants, NOx and PM10, as well as the traffic flow data.

Since to perform the experimental campaign the avenue was divided in five links, it was possible to assess the high emission hotspots through that road. High emission hotspots were achieved in the link 2 and 3 (L2 and L3 in Fig. 1), with a daily average emission of $0.44 \mathrm{~g}^{\cdot \mathrm{km}^{-1}}$ and 0.22 $\mathrm{g} \cdot \mathrm{km}^{-1}$ of NOx, respectively for VSP and TREM models; average PM10 emissions of $0.03 \mathrm{~g} \cdot \mathrm{km}^{-1}$ [VSP] and $0.006 \mathrm{~g} \mathrm{~km}^{-1}$ [TREM] were obtained. These links are closely located to the school placed in the study domain, where the daily average speed is low $\left(<30 \mathrm{~km} \cdot \mathrm{h}^{-1}\right)$ related to the presence of intersections, traffic lights and the existence of pick up and drop off points, which increases stop-and-go situations. Consequently, these speed changes contribute to increased total emission levels per vehicle. Analysing the daily traffic volume data (vehicles $\cdot h^{-1}$ ), it is observed a clear traffic dynamic behaviour, with distinct peak periods, 8-9 a.m. (with a traffic volume of 965 vehicles, accounting for $6.7 \%$ of the total daily volume) and 6-7 p.m. (with a traffic volume of 1166 vehicles, accounting for $8.1 \%$ of the total daily volume), and off-peak periods, 0 7 a.m. (with an average traffic volume of 63 vehicles, which represents around $0.4 \%$ of the total daily volume), which follows a typical daily traffic profile at urban environments (Coelho et al., 2014). The work of Coelho et al. (2014) showed that in Portuguese urban roads the peak periods occurs between 7-9 a.m. and 6-7 p.m., being conjointly responsible for around $16 \%$ of the total daily volume; the off-peak periods occurs during the night-time (0-7 a.m.) and between 10 a.m.5 p.m.. In addition, the field campaign have shown that even during off-peak periods, a low volume/capacity is maintained.

The daily emissions of NOx and PM10 $\left(\mathrm{g} \cdot \mathrm{h}^{-1}\right)$ recorded for the study area, for all the emission models applied, follows the hourly road traffic volume. As a result, high values of road traffic emissions, varying according with the emission model used, with values of $286.2 \mathrm{~g}$ [TREM] and $477.3 \mathrm{~g}$ [VSP] for NOx and in $14.5 \mathrm{~g}$ [TREM] and $49 \mathrm{~g}$ [VSP] for PM10, were obtained for the peak periods (hourly average of the morning and afternoon peaks). Therefore, the fluctuation of traffic volumes over the day is one of the main factors determining the hourly total emissions. In addition, two distinct inferences can be made: i) road traffic shows higher emission levels of NOx $(89.7 \%$ [VSP] - 94\% [TREM] higher than PM10 emissions at peak periods) across the day; ii) different emission models promotes different emission levels.

Regarding the first feature, it is observed that NOx emissions are, in average, 95\% higher [TREM] than the PM10 emission (a value of $90.3 \%$ was obtained for the case of VSP model). This is a result of the emission factors considered in each model, higher for NOx, which are in accordance with European data. At European level for 2015, the road transport sector contribute around 30\% and $3.5 \%$ for the total of NOx and PM10 emissions (a ratio of around 8.6), respectively (EEA, 2017). Concerning the second feature, it is clear that the emissions estimated by the TREM model, for both air pollutants, presents lower magnitude, $-45.3 \%$ [NOx] and $-90.4 \%$ [PM10] at peak periods, when compared with the VSP model values. These differences can be explained by the emission calculation method implemented at each model. As previously mentioned, VSP is an instantaneous emission models based on second-by-second vehicle dynamics and clearly include congestion in the modelling process, while the TREM model considers an average vehicle speed where the emission rates are calculated based on standardized driving cycles (Smit et al., 2008). 
(a)

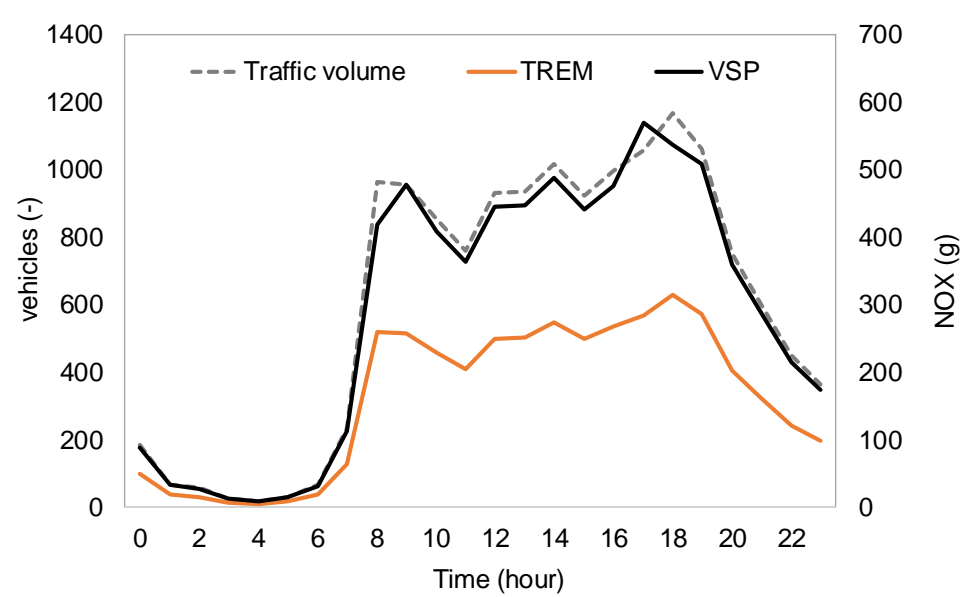

(b)

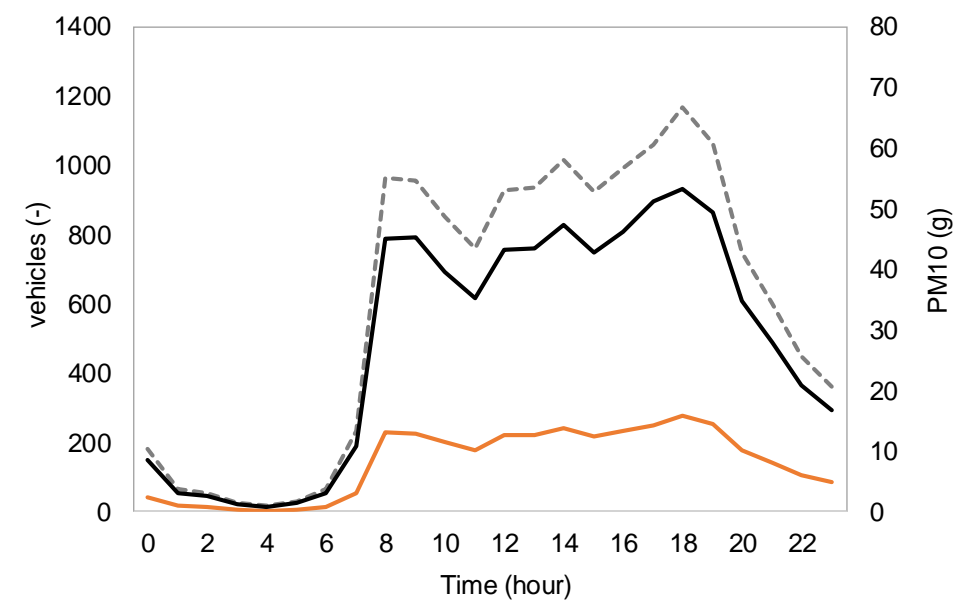

Fig. 6. Traffic emissions for $7^{\text {th }}$ of February of 2017 for the two analysed pollutants, (a) NOx and (b) PM10, estimated according different emission approaches. The daily traffic volume is presented on the left axis (dashed line), while the emission rate is shown on the right axis.

\subsubsection{Air quality: local measurements and modelling}

The air quality status of the study area was investigated following two distinct approaches: i) analysis of the NOx and PM10 concentrations daily profile, based on measured data acquired in two air quality monitoring stations, which allows a characterization of air pollutant concentrations time evolution (Fig. 7); ii) spatiotemporal analysis, through the mapping of PM10 and NOx hourly concentrations, based on the modelled data considering the emissions estimated by the different approaches under study, which allows an understanding of the spatial variability of the air pollutants concentration (Fig. 8).

Fig. 7 shows the measured PM10 and NOx concentrations daily profile, based on acquired data in two air quality stations (Urb. and Back. stations) for the period of the experimental campaign. In the case of PM10 concentrations, for the reporting period, the maximum value at the urban station was $32.4 \mu \mathrm{g} \cdot \mathrm{m}^{-3}$ at $11 \mathrm{p} . \mathrm{m}$. (with a minimum value of $13 \mu \mathrm{g} \cdot \mathrm{m}^{-3}$ at $2 \mathrm{p} . \mathrm{m}$.); for the period of higher traffic volume ( 8 a.m. and $7 \mathrm{p} . \mathrm{m}$.) the measured PM10 concentration was $19 \mu \mathrm{g} \cdot \mathrm{m}^{-3}$. All these values are below the daily limit-value established by Directive 2008/50/CE $\left(50 \mu \mathrm{g} \cdot \mathrm{m}^{-3}\right)$ and closely to the average value registered in $2016,20 \mu \mathrm{g} \cdot \mathrm{m}^{-3}$. From the analysis of Fig. 7 , it is evident that the daily profile of PM10 concentrations at both stations does not shows a clear linkage with the daily road traffic volume. In fact, the PM10 daily profile at both measured stations are in accordance with the expected daily profile for a winter period (Gama et al., 2018), when the nonroad traffic emission can have a more important role in PM10 concentrations. Concentrations 
decrease during the day from mid-morning to early evening. At night, the decrease occurs following the evening peak between midnight and roughly 5 a.m. The amplitude of variation is higher at night than during the afternoon. Regarding $\mathrm{NOx}$, the maximum concentration value at the urban station is obtained at 8-9 a.m. (peak period), $27.2 \mu \mathrm{g} \cdot \mathrm{m}^{-3}$, followed by a value of 22.7 $\mu \mathrm{g} \cdot \mathrm{m}^{-3}$ at 6-7 p.m. (peak period); a minimum value of $6.6 \mu \mathrm{g} \cdot \mathrm{m}^{-3}$ is obtained at $5-6 \mathrm{a} \cdot \mathrm{m}$. (of-peak period). It is evident that the daily profile of NOx concentrations follows the hourly road traffic volume, at both stations (see Fig. 7), following the emissions profile. It is interesting to note that different magnitudes of NOx concentrations were obtained in the peak periods, despite the slight difference in the road traffic volume, especially knowing that a high road traffic volume was obtained at 6-7 p.m. These differences are a result of the meteorological conditions. In the morning peak a wind velocity of $1.9 \mathrm{~m} \cdot \mathrm{s}^{-1}$ was registered, while at the afternoon peak a wind velocity of $3.7 \mathrm{~m} \cdot \mathrm{s}^{-1}$ was obtained; for both periods the wind blows from north-northwest. This means that for a similar emission rate, the air quality is highly dependent of the meteorological conditions, with high values of wind velocity promoting the dispersion of air pollutants. The measured NOx concentrations are significantly lower than the limit-value $\left(200 \mu \mathrm{g} \cdot \mathrm{m}^{-3}\right.$, in an hourly basis), but higher than the average value registered in 2016, $22.7 \mu \mathrm{g} \cdot \mathrm{m}^{-3}$. Despite both air pollutant concentrations were below the limit-value, should be noticed that the proximity of a school is a critical issue. The study of Valente et al. (2014), for the same area, shows that the daily indoor PM10 concentration during occupancy periods were 2 to 4 times higher than the concentrations registered outdoors, which could mean that the resident population (students and people who lives in this neighbourhood) could be exposure to high levels of PM10 concentrations.

434 For the urban traffic station, the data of last 5-years (2012-2016) of PM10 and NOx concentrations were also analysed to assess the trend lines (Fig. S1 and Fig. S2 in the Supporting Information). The results shows a concentration reduction trend for both pollutants through the years; the annual PM10 concentration in $2016\left(20 \mu \mathrm{g} \cdot \mathrm{m}^{-3}\right)$ was $43 \%$ less than the value registered in 2012 $\left(35 \mu \mathrm{g} \cdot \mathrm{m}^{-3}\right)$, while for NOx, the annual concentration in $2016\left(29.5 \mu \mathrm{g} \cdot \mathrm{m}^{-3}\right)$ was $6 \%$ less than the value registered in $2012\left(31.4 \mu \mathrm{g} \cdot \mathrm{m}^{-3}\right)$ (see Table S1 in the Supporting Information). High PM10 concentrations were always registered in the winter months (December-February). Since no noteworthy changes occurs in the road traffic volume in these months (compared with the entire year), these data highlights the influence of non-road emission sources to the air quality of the study area. NOx concentrations shows a systematic daily profile, with high concentrations at 8-9 a.m. and 6-7 p.m. periods, consistent with the high daily traffic volume. The statistical comparison between the experimental campaign time-series acquired in background station shows a high correlation $(r=0.85)$ for hourly average NOx values. Although for PM10 a lower agreement $(r=$ 0.79 ) was obtained, the magnitude presented in the suburban background station measurements is, for the majority of the time-series, lower than that from the urban station. This indicates that Back. is representative of Aveiro's background in the period under analysis. 
(a)

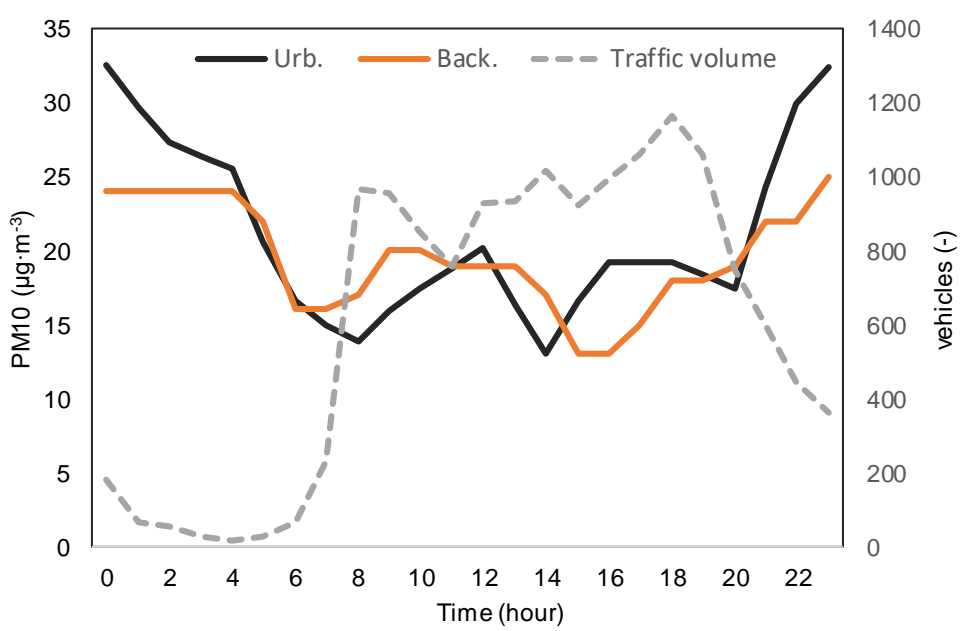

(b)

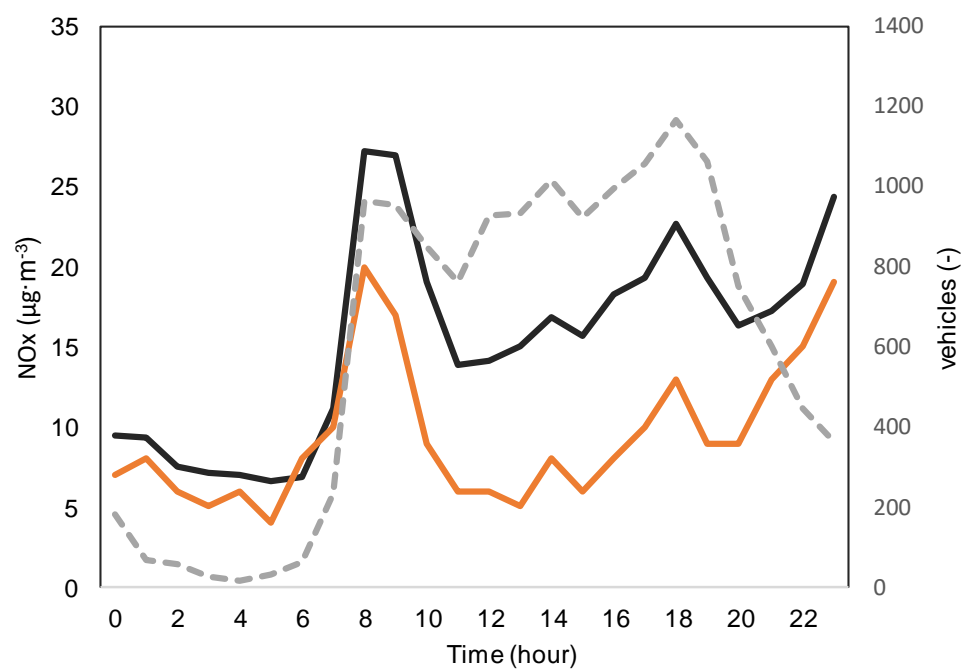

Fig. 7. Daily profile of (a) PM10 and (b) NOx concentration in the two air quality stations (urban traffic station [Urb.] and suburban background station [Back.]) for the 7th of February of 2017. The daily traffic volume (dashed line) is presented on the right axis.

Fig. 8 shows, by way of example, NOx and PM10 concentrations fields for the emission models under study for $3 \mathrm{~m}$ high horizontal streamlines, for the 8-9 a.m. period. The results shows that the analysed pollutants behave in a similar way across the domain (especially the concentration peaks distribution), independently of the emission model used to estimate the road traffic emissions. High concentrations were obtained nearby the school, which is a result of conjoint influence of high emissions (Links L2 and L3) and unfavourable conditions for air pollutants dispersion. This last feature is related to the characteristics of the urban morphology over the wind flow, that promotes the existence of recirculation areas between buildings and trees, zones characterised by a low wind velocity (average values of $0.9 \mathrm{~m} \cdot \mathrm{s}^{-1}$ for a wind inflow of $2 \mathrm{~m} \cdot \mathrm{s}^{-1}$ were obtained; for a maximum wind inflow of $5.4 \mathrm{~m} \cdot \mathrm{s}^{-1}$ [at $12 \mathrm{a} . \mathrm{m}$.], a value of $3 \mathrm{~m} \cdot \mathrm{s}^{-1}$ was obtained), and so an accumulation of air pollutants concentration is endorsed. Analysing the study area as an all, for a spatial average, a wind velocity of $2.5 \mathrm{~m} \cdot \mathrm{s}^{-1}$ (daily average) was obtained; a maximum wind velocity of $12 \mathrm{~m} \cdot \mathrm{s}^{-1}$ (occurred at the beginning of the avenue) was obtained at 6 a.m. (for a wind flow of $3.7 \mathrm{~m} \cdot \mathrm{s}^{-1}$ ), when the domain in perfectly aligned with wind direction. 

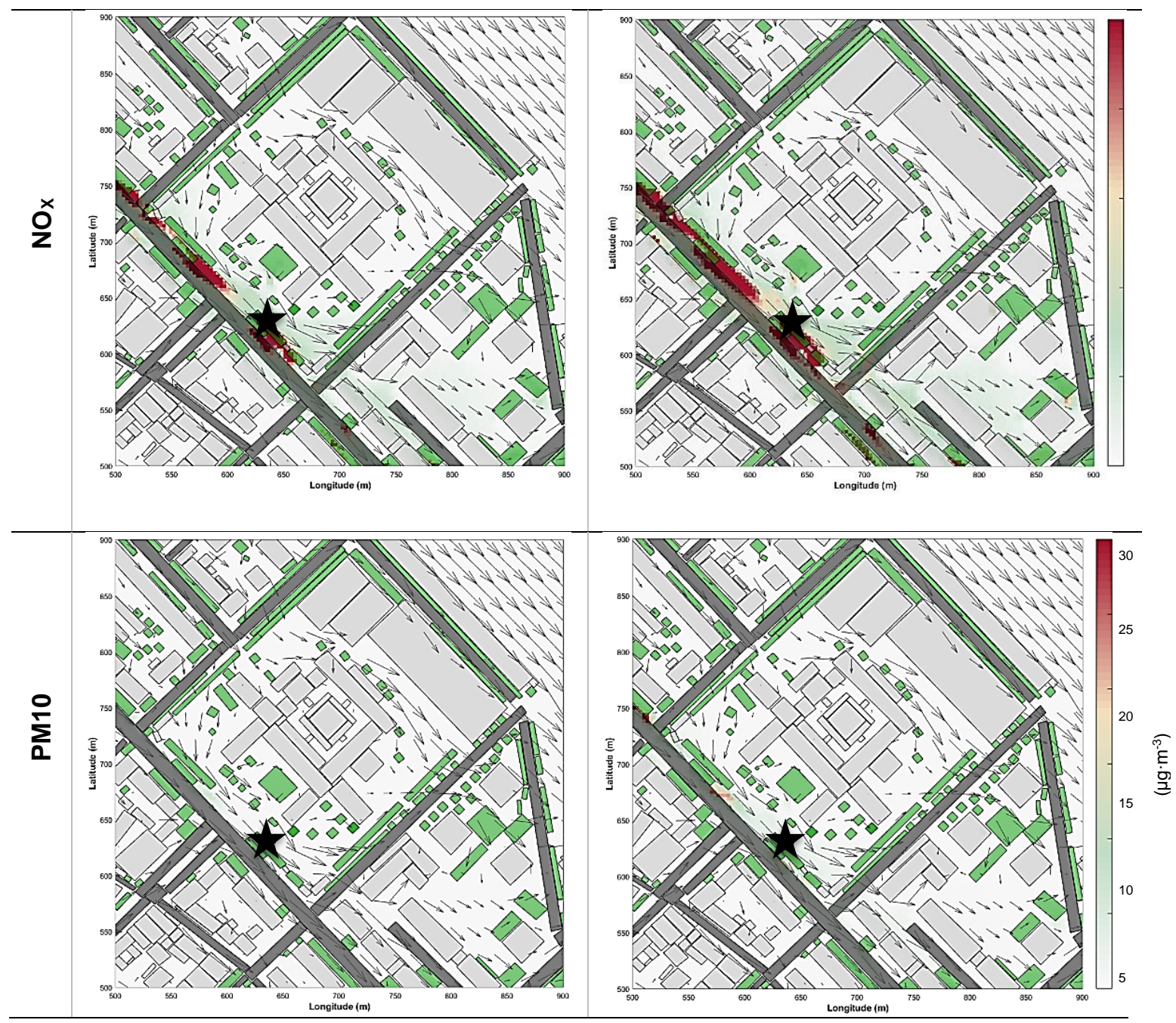

Fig. 8. NOx and PM10 concentrations fields for the emission models under study for $3 \mathrm{~m}$ high horizontal streamlines. Contours refer to the period of 8 a.m. (with an inflow wind velocity of $1.9 \mathrm{~m} \cdot \mathrm{s}^{-1}$ and a wind direction of $\left.308^{\circ}\right)$. The arrows represent the wind flow behaviour (velocity and direction) within the computational domain. The black star shows the Air Quality Station's location.

Daily average PM10 concentrations related to road-traffic emissions of $0.2 \mu \mathrm{g} \cdot \mathrm{m}^{-3}[\mathrm{VSP}$ ] (ranging between 0.002 [at 4 a.m.] and $0.74 \mu \mathrm{g} \cdot \mathrm{m}^{-3}$ [at $8-9$ a.m.]) was obtained for a spatial average of the domain; an average value of $0.06 \mu \mathrm{g} \cdot \mathrm{m}^{-3}$ was obtained when the TREM model was used to estimate the emissions. For this pollutant, a maximum value of $57 \mu \mathrm{g} \cdot \mathrm{m}^{-3}$ [VSP] was obtained at 8 a.m., in specific zones of the domain (near links L2 and L3); a maximum value of 17.1 was obtained considering TREM emissions, at the same time period. PM10 levels higher than $5 \mu \mathrm{g} \cdot \mathrm{m}^{-}$ ${ }^{3}$ were obtained at $7 \%$ of the domain cells, for both emission models. In the case of NOx concentrations, a daily average values of $2.1 \mathrm{\mu g} \cdot \mathrm{m}^{-3}$ [VSP] and $1.2 \mu \mathrm{g} \cdot \mathrm{m}^{-3}$ [TREM] were obtained, considering a spatial average of the domain. Maximum NOx levels were obtained for the same areas previously identified for PM10 concentrations, with maximum values of $485 \mu \mathrm{g} \cdot \mathrm{m}^{-3}$ [VSP] and $331.7 \mu \mathrm{g} \cdot \mathrm{m}^{-3}$ [TREM], at 8-9 a.m. NOx concentrations higher than the limit-value were obtained in around $0.1 \%$ of the domain cells, for all the analysed emission models; $2 \%$ of the domain displaced NOx concentrations higher than $50 \mu \mathrm{g} \cdot \mathrm{m}^{-3}$.

The dynamics of traffic (and related emissions, as already discussed in section 3.1.1.) and atmospheric conditions (wind velocity and wind direction) become evident in the magnitude of PM10 and NOx concentrations, at both measured and modelled data, as well as, in the location 
of the NOx and PM10 hotspots (for modelled data). A correlation analysis was made to evaluate the relative importance of the meteorological conditions and the traffic emissions to the modelled air quality levels. Should be noted that due to complex interactions that occurs at the urban environment, the correlation analysis cannot directly reflect the absolute influence of different factors, but can provide important insights about its relative importance (Chen et al., 2017). For both pollutants, a strong correlation was obtained between the traffic emissions and the air pollutants concentrations. Traffic emissions explains $54 \%$ (when the VSP model is used) and $61 \%$ (when the TREM model is used) of the NOx concentrations, while the PM10 concentrations are explained in $62 \%$ (for both models). Regarding the meteorological conditions, the wind velocity shows a more noteworthy role in the air quality levels than the wind direction; wind velocity explains around $58 \%$ of PM10 and NOx concentrations. It was also concluded that the wind velocity and air pollutants levels varies in an inverse way, which implies that the NOx and PM10 concentrations increase with a decrease of the wind velocity.

\subsection{Comparative analysis of emission approaches}

To assess the influence of different emission approaches in the accuracy of numerical simulations, two analysis were carried out: i) a quantitative evaluation based on a set of statistical metrics; and ii) a qualitative evaluation based on graphic visualization, through inter-modelling time-series plots. Both analysis were performed considering only the effect of local emissions to the air quality, and adding the contribution of background emission sources. This means that two datasets were used to evaluate the accuracy of numerical simulations (both were compared with the measured data acquired in the urban traffic station): i) modelled data only, and ii) modelled data plus measured background concentrations; the background concentrations from the suburban background station (see section 2.3), for the experimental period, were added hour-byhour to the modelled data. In the scope of this work, the background concentration is defined as the concentration that would be measured in the absence of local emission sources that are explicitly considered by the dispersion model. Therefore, the background air quality should include a contribution of all other sources, natural and anthropogenic, except local traffic emissions considered in the model inputs, giving an outlook of the relative contribution of nonroad emissions to the local air quality.

The statistical metric were calculated by applying model acceptance criteria proposed by Chang and Hanna (2004) for air quality models assessment, which establishes performance measures for the normalized mean square error (NMSE $<1.5)$, fraction of predictions within a factor of two of observations (FAC2 > 0.5) and the mean bias (MBE < 0.3). Also the average value (MEAN), the correlation coefficient ( $r$ ) and the standard deviation (SIGMA) were considered in the analysis. The performance measures were calculated applying the BOOT Statistical Model Evaluation Software Package (Chang and Hanna, 2004).

Table 2 compiles the statistics for the comparison between model outputs and air quality measurements of PM10 and NOx levels considering the hourly data. Aiming to distinguish the effect of the background concentration on VADIS performance, both the direct modelled output and with background are shown.

As can be seen, for NOx, model acceptance criteria were fulfilled for the different emission models used, with a similar performance; main differences were obtained for the MBE parameter, with both models promoting an underestimation (negative values) of modelled concentration data, more pronounced when TREM was used. In general, a good correlation (higher than 0.8 ) between modelled and measured data was obtained, independently of the emission model used. The conjoint analysis of all the statistical parameters showed that VSP is the model that allows a better performance of the air quality model, and so a better estimation of traffic-related NOx emission, 
related to the ability of the model to realistic reproduce the different driving modes (e.g., acceleration/deceleration). The results also highlight the potential of detailed traffic and instantaneous exhaust emissions estimates to provide accurate input data to CFD models applied at local scale. These findings are in accordance with the outcomes of studies conducted at urban scale (Borrego et al., 2016; Amirjamshidi et al., 2013; Misra et al., 2013). A slight improvement of the statistical parameters was obtained when the background contribution was added; however an overestimation (positive MBE), more pronounced with VSP model, was obtained. These results reinforced the road traffic as the main emission source at urban areas. A very different behaviour was obtained for PM10. In general, and for all emission models, the model acceptance criteria were not fulfilled. In fact, a negative correlation was obtained meaning an inverse relationship between the modelled and measured data. A clear underestimation of PM10 concentrations was obtained (negative MBE), with high values of both MBE (with values of -20.7 [TREM] and -19.6 [VSP], according to the emission model used) and NMSE. To these results two main issues may have contributed: i) a underestimation of PM10 emissions, mainly related to the fact that non-exhaust PM10 emissions has not been estimated; this is particularly important since during the experimental campaign the roads were dry (no precipitation have occurred during this period) and so, PM10 resuspension can be an important emission source (the relative importance of non-exhaust emissions has been increasing as a result of the introduction of vehicle particulate abatement technologies [EEA, 2017]); ii) influence of other emission sources.

A consistent improvement of model accuracy results from adding the background contribution with a substantial increases of the average $r$, with values of 0.62 [VSP] $(-0.39$ without the background) and 0.76 [TREM] (-0.38 without the background). The model acceptance criteria for the NMSE and FAC2 were fulfilled, despite some underestimation (by both models), revealed by the negative MBE. The FAC2 parameter, a robust performance measure in the evaluation of CFD models, shows that, in average, $100 \%$ of the hourly predictions ( $0 \%$ with no background) are within a factor of two of the observations.

Table 2. Statistics of VADIS performance of PM10 and NOx evaluated against observations, without and with (in brackets) the contribution of background concentrations, for the analysed period. In the analysis, 24 data points (hourly averages) were considered for both pollutants. A positive MBE indicates here an over prediction.

\begin{tabular}{|c|c|c|c|c|c|c|}
\hline & $\begin{array}{l}\text { MEAN } \\
\left(\mu \mathrm{g} \cdot \mathrm{m}^{-3}\right)\end{array}$ & SIGMA & $\operatorname{MBE}\left(\mu \mathrm{g} \cdot \mathrm{m}^{-3}\right)$ & NMSE & $\mathbf{R}$ & FAC2 \\
\hline AQS & 15.43 & 6.20 & - & 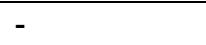 & - & - \\
\hline o̊ TREM & $8.43(17.89)$ & $8.51(\mathbf{1 2 . 3 0})$ & $-7.00(+$ & $0.49(\mathbf{0 . 2 0})$ & $0.91(\mathbf{0 . 9 1})$ & $0.38(\mathbf{1 . 0 0})$ \\
\hline VSP & $14.31(23.77)$ & $14.87(18.44)$ & $-1.12(+8.34)$ & $0.45(\mathbf{0 . 6 6})$ & $0.88(\mathbf{0 . 9 0})$ & $0.63(\mathbf{0 . 8 8})$ \\
\hline \multirow{3}{*}{$\begin{array}{l}\text { AQS } \\
\text { 을 TREM } \\
\sum_{\text {L }} \text { TSP }\end{array}$} & 21.10 & 5.78 & 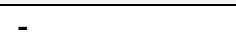 & 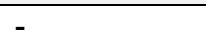 & & \\
\hline & $0.43(20.02)$ & $0.43(3.45)$ & $-20.66(-1.08)$ & $50.42(\mathbf{0 . 0 4})$ & $-0.38(\mathbf{0 . 7 6})$ & $0.00(\mathbf{1 . 0 0})$ \\
\hline & $1.49(\mathbf{2 1 . 0 0})$ & 1.49 (3.59) & $-19.61(-0.09)$ & $13.60(0.05)$ & $-0.39(\mathbf{0 . 6 2})$ & $0.00(\mathbf{1 . 0 0})$ \\
\hline
\end{tabular}

Aiming to further investigate the dependency of model performance on the time of the day, measured versus modelled daily mean profiles of hourly surface pollutant concentration were calculated. This analysis is also provided considering the influence of background concentrations. The measured data was provided by the urban air quality monitoring station. Fig. 9 depicts the ability of the modelling approach to track the evolution of NOx levels, including the morning traffic peak at 8-9 a.m. (Fig. 9a). These data shows that in the study area, the NOx concentrations are mainly caused by traffic-related NOx emission, accounting (in a daily average) for $72.9 \%$ [TREM] and $89.5 \%$ [VSP] of the total NOx concentrations measured in the air quality station. Fig. 9 also 
shows that background concentrations have an influence during off-peak periods (shown by the fit between measured and modelled NOx concentrations at these periods when the background concentrations are added to the modelled results). The daily profile reveals an overestimation of NOx concentrations at sunrise (8-9 a.m.), more pronounced when the VSP model is used and when the background concentrations are added to the modelled values. This overestimation reinforces the linkages between road traffic emissions and NOx concentrations, since considering the influence of other emission sources increases the bias between measured and modelled data. For this pollutant, the background conditions should only be consider when a low road traffic volume is recorded. The origin of this large overestimation is probably due to the conjoint influence of an overestimation of traffic emissions and of unfavourable conditions to air pollutants dispersion. At this period a very low wind velocity $\left(0.9 \mathrm{~m} \cdot \mathrm{s}^{-1}\right)$ was modelled. Despite the VADIS model have been validated through time, as discussed by Rafael et al. (2018), a model is merely a model of reality, and so, its use induces a certain level of uncertainty.

An agreement between measured and modelled concentrations was not observed for PM10 (Fig. 9c). It is clearly visible that the modelled and measured PM10 concentrations shows a distinct daily profile, which are in line with the statistical analysis (negative correlation factor). The high MBE values obtained in the statistical analysis are also clear along the time series, as well as the response of the CFD VADIS to the different emissions provided (traduced by differences in the magnitude of PM10 concentrations). However, it is evident that these differences were not enough to imply noteworthy differences in terms of the daily profile of the modelled results, being the traffic-related PM10 emissions responsible (in a daily average) for $1.3 \%$ [TREM] and $8.4 \%$ [VSP] of the total PM10 concentrations measured in the air quality station. These values are in accordance with the air pollution statistical fact sheet (2017) for Portugal (URL1), which shows that road transport contributes $6.7 \%$ for the total of PM10 emissions. Maximum linkage were obtained at the morning peak period (8 a.m. -9 a.m.) with values of $9 \%$ [TREM] and $37 \%$ [VSP]. These results can denote one of two issues: $i)$ the VADIS model is not able to accurately simulate PM10 concentrations; ii) the traffic-related PM10 emission is only one source contributing to PM10 concentrations in the study area. When the background concentrations were added to the modelled results (Fig. 9d), it was observed an improvement in the fitting between the measured and modelled daily profile; modelled results obtained by using emissions estimated by TREM model shows a better link with the measured data, which is in line with the statistical parameters. This means that other emission sources, beyond road traffic sector, have an important contribution to PM10 concentrations. The study of Alves et al. (2014) focused in the same study area, have identified a set of PM10 emission sources related to combustion processes coming from nearby restaurants and bakeries with charcoal and firewood use. Additionally, and taking into account that the experimental campaign took place during winter, the contribution from domestic woodstoves and fireplaces should be substantial. In fact, several studies pointed out residential combustion (in particular wood burning) as a major source contributing to PM10 concentration levels during winter time in many regions across Europe (Borrego et al. 2010; Bernardoni et al. 2011; Karvosenoj et al. 2011; Fuzzi et al. 2015; Viana et al. 2013; Waked et al. 2014). Borrego et al. (2010) have determined the PM10 diurnal average pattern by season over Portugal, based on the monitoring stations network. In the winter and autumn seasons, two peaks in average concentration were obtained: one in the morning between 7 and 11 a.m., and the other in the evening between 7 and $10 \mathrm{p} . \mathrm{m}$. The existence of these peaks, distinguished from those obtained at spring and summer daily profile, is explained by home heating during the early morning and evening hours. This daily behavior is in accordance with the profile obtained in the urban traffic station, which is well reproduced when the background conditions are added to the modelled results. This issue was recently reinforced by the study of Gama et al. (2018), which provides a long-term characterization of temporal patterns and trends of particulate matter over Portugal. The results showed that the late evening peak is stronger during the winter as result of both the daily evolution of the atmospheric boundary layer, which gets thinner during the night, 

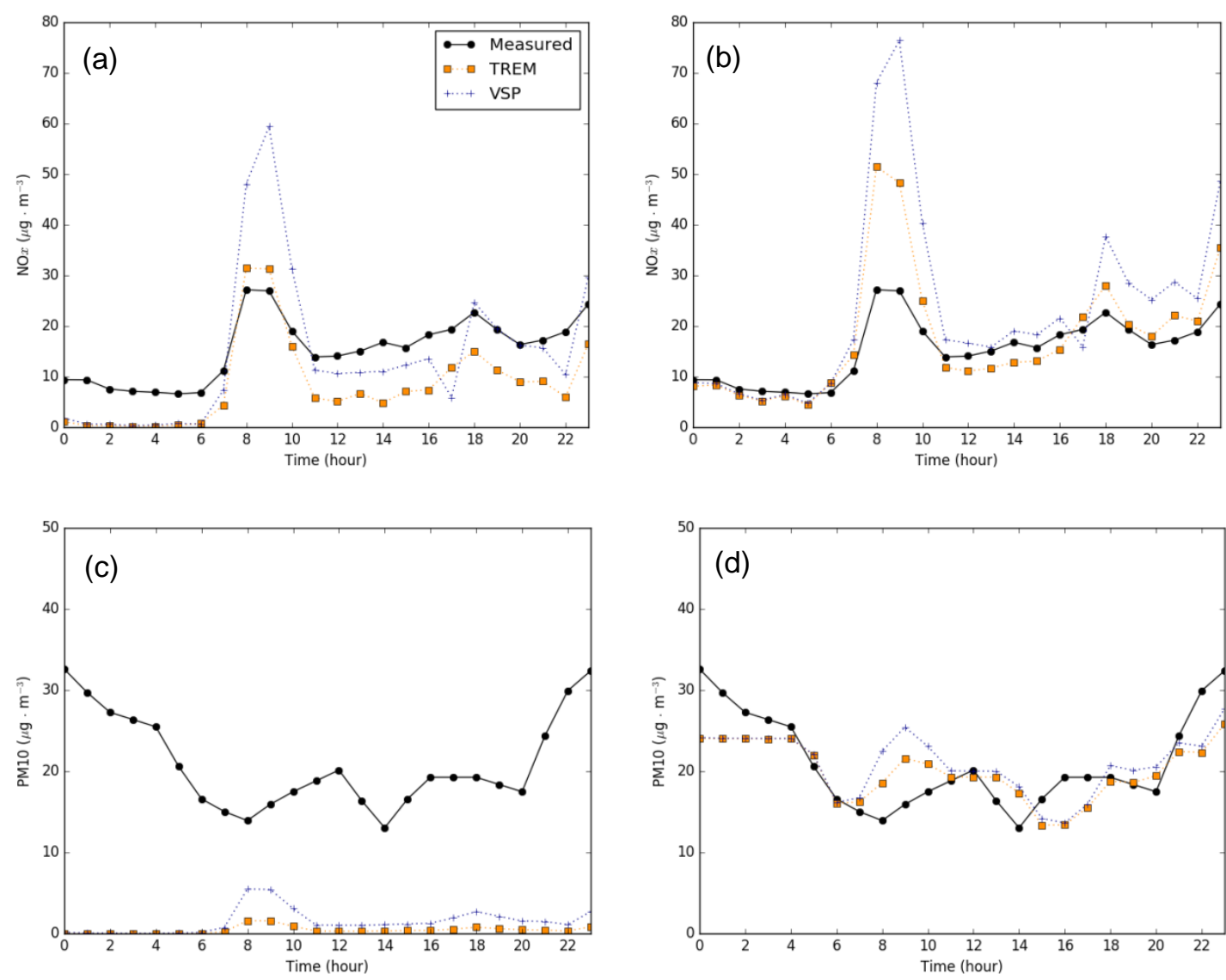

631

632

633

634

635

\section{6}

637

638

639

640

641

642

643

Fig. 9. Daily profile of NOx and PM10 concentrations, for both measured and modelled data, for the experimental period $(\mathrm{a}, \mathrm{c})$. Comparison between the daily profile of modelled data considering the addition of NOx and PM10 background concentration and the measured data is also showed (b, d). Modelled results obtained considering different emission modes are presented.

\section{Conclusions}

In this work the air quality of a main avenue of a medium-size European city was simulated, with street level resolution, for a weekday period (typical winter day in terms of both emissions and meteorological conditions). A modelling approach was applied consisting of (1) detailed traffic flows obtained by an experimental campaign conducted for the study period; (2) exhaust road traffic emissions estimated by two different approaches, VSP and TREM; and (3) air pollutants dispersion, focused on NOx and PM10, simulated by the CFD model VADIS.

Both emission models show for NOx emissions similar patterns in the emissions daily profile with a good correlation between the traffic dynamics and the emissions daily profile; however, notable differences in terms of the magnitude of the obtained values were observed. Regarding PM10, the differences in the complexity level of the emission models were evident in magnitude of the estimated emissions and at the PM10 concentrations obtained with VADIS. The analysis of model performance metrics showed that, for NOx, the data quality objective were fulfilled, with a better performance (even slight) when the VSP model is used; these findings implies that the NOx concentrations are mainly caused by traffic-related NOx emission, accounting for $72.9 \%$ [TREM] 
and $89.5 \%$ [VSP] of the total NOx concentrations measured in the air quality station. However, an overestimation of the NOx concentrations (more noteworthy when the background concentrations are added) was observed at the morning peak, independently of the emission model used (but more pronounced when VSP was applied), which can point to an overestimation of traffic emissions. Contrariwise, a negative correlation between measured and modelled values, independently of the emission model used, were obtained for PM10 concentrations. Correlation ( 0.7 [TREM] and 0.6 [VSP]), as well as all the statistics metrics analysed, were shown to considerably improve when urban background concentration is added. This means that other emission sources, beyond road traffic sector (this only accounts for $1.3 \%$ [TREM] and $8.4 \%$ [VSP]) have an important contribution to PM10 concentrations; taking into account that the experimental campaign took place during winter, the contribution of the residential sector (combustion of fired used in domestic woodstoves and fireplaces) should be substantial.

663 This study showed that despite the developments on air quality models, road traffic emissions are still a variable of fundamental relevance in the global accuracy of simulations, especially at local scale. In general, the results highlight the potential of detailed traffic and instantaneous exhaust emissions estimates, together with urban background, to provide accurate input data to CFD models applied at the local scale. Additionally, since mobility improvement while at the same time reducing air pollution, are common challenges to all major cities in Europe, this type of studies allow an assessment of the different origins of air pollution, and so, the definition of sectoral measures to improve air quality taking into account specific characteristics of each city.

\section{Acknowledgments}

673 The authors acknowledge the support of @CRUiSE project (PTDC/EMS-TRA/0383/2014, funded 674 within the Project 9471 - Reforçar a Investigação, o Desenvolvimento Tecnológico e a Inovação 675 (Project 9471 - RIDTI) and supported by the European Community Fund FEDER). CESAM co676 authors acknowledge the financial support of the FCT/MEC through national funds, and the 677 cofounding by the FEDER, within the PT2020 Partnership Agreement and Compete 2020, for the 678 research project CESAM (UID/AMB/50017-POCI-01-0145-FEDER-007638). TEMA co-authors 679 also acknowledge: Project CISMOB (PGI01611 funded by Interreg Europe Programme), Strategic 680 Project UID-EMS-00481-2013 (FCT - Portuguese Science and Technology Foundation), 681 CENTRO-01-0145-FEDER-022083, and MobiWise project (P2020 SAICTPAC/0011/2015) (co682 funded by COMPETE2020, Portugal2020 - Operational Program for Competitiveness and 683 Internationalization (POCI), European Union's ERDF (European Regional Development Fund), 684 and FCT), FCT Scholarship SFRH/BPD/100703/2014 and Caetano Auto S.A. Portugal 685 (representatives of Toyota).

\section{References}

ACAP (Associação Automóvel de Portugal) (2015) Portugal Statistics for fleet composition. Available from: http://www.acap.pt/.

690 Alves CA, Urban RC, Pegas PN, Nunes T (2014) Indoor/Outdoor relationships between PM10 and 691 associated organic compounds in a primary school. Aerosol Air Qual Res 14:86-98. https://doi: 692 10.4209/aaqr.2013.04.0114

693 Amirjamshidi G, Mostafa TS, Misra A, Roorda MJ (2013) Integrated model for microsimulating vehicle 694 emissions, pollutant dispersion and population exposure. Transport Res D-Tr E 18: 16-24. 695 https://doi.org/10.1016/..trd.2012.08.003 
Amorim J, Rodrigues V, Tavares R, Valente J, Borrego C (2013) CFD modelling of the aerodynamic effect of trees on urban air pollution dispersion. Sci Total Environ 461: 541-551. 698 https://doi.org/10.1016/i.scitotenv.2013.05.031

699 Bernardoni V, Vecchi R, Valli G, Piazzalunga A, Fermo P (2011) PM10 source apportionment in Milan (Italy) using time-resolved data. Sci Total Environ 409: 4788-4795. https://doi.org/10.1016/i.scitotenv.2011.07.048

Borrego C, Tchepel O, Barros N, Miranda A (2000) Impact of road traffic emissions on air quality of the Lisbon region. Atmos Environ 34: 4683-4690. https://doi.org/10.1016/S1352-2310(00)00301-0

Borrego C, Tchepel O, Costa A, Amorim J, Miranda A (2003) Emission and dispersion modelling of Lisbon air quality at local scale. Atmos Environ 37: 5197-5205. https://doi.org/10.1016/j.atmosenv.2003.09.004

Borrego C, Tchepel O, Salmim L, Amorim J, Costa A, Janko J (2004) Integrated modeling of road traffic emissions: application to Lisbon air quality management. Cybern Syst Int J 35: 535-548. https://doi.org/10.1080/0196972049051904

Borrego C, Valente J, Carvalho A, Sa E, Lopes M, Miranda Al (2010) Contribution of residential wood combustion to PM10 levels in Portugal. Atmos Environ 44: 642-651. https://10.1016/.atmosenv.2009.11.020

Borrego C, Amorim JH, Tchepel O, Dias D, Rafael S, Sá E, Pimentel C, Fontes T, Fernandes P, Pereira SR, Bandeira JM, Coelho MC (2016) Urban scale air quality modelling using detailed traffic emissions estimates. Atmos Environ 131: 341-351. https://doi.org/10.1016/j.atmosenv.2016.02.017

713 Chang JC, Hanna SR (2004) Air quality model performance evaluation. Meteorol Atmos Phys 87:167-196. 714 https://10.1007/s00703-003-0070-7

715 Chen Z, Cai J, Gao B, Xu B, Dai S, He B, Xie X (2017) Detecting the causality influence of individual 716 meteorological factors on local PM2.5 concentration in the Jing-Jin-Ji region. Scientific Reports 7: 1-11. 717 https://doi.org/10.1038/srep40735

718 Coelho MC, Fontes T, Bandeira JM, Pereira SR, Tchepel O, Dias D, Sá E, Amorim JH, Borrego C (2014) 719 Assessment of potential improvements on regional air quality modelling related with implementation of a detailed methodology for traffic emission estimation. Sci Total Environ 470: 127-137. https://doi.org/10.1016/j.scitotenv.2013.09.042

722 Costa S, Ferreira J, Silveira C, Costa C, Lopes D, Relvas H, Borrego C, Roebeling P, Miranda Al, Teixeira

JP (2014) Integrating health on air quality assessment-review report on health risks of two major European outdoor air pollutants: PM and NO2. J Toxicol Environ Health Part B 17: 307-340. https://doi.org/10.1080/10937404.2014.94616

EMEP/EEA 2010. Passenger Cars, Light-Duty Trucks, Heavy-Duty Vehicles Including Buses and Motor Cycles. European Monitoring and Evaluation Programme (EMEP) Air Pollutant Emission Inventory Guidebook 2009, updated June 2010. Technical report No 9/2009. 129 p

Emisia SA, Copert data, downloaded 9 of April 2017. Available from: http://emisia.com/products/copert-data

730 European Environment Agency (EEA) (2014) Air Quality in Europe - 2014 report, EEA Report No 5/2014. 731 Copenhagen. Luxembourg: Publications Office of the European Union

732 European Environment Agency (EEA) (2015a) Evaluating 15 years of transport and environmental policy 733 integration - 2015 report, EEA Report No 7/2015. Copenhagen. Luxembourg: Publications Office of the 734 European Union

735 European Environment Agency (EEA) (2015b) Air Quality in Europe - 2015 report, EEA Report No 5/2015. 736 Copenhagen. Luxembourg: Publications Office of the European Union

737 European Environment Agency (EEA) (2016a) Air Quality in Europe - 2016 report, EEA Report No 5/2016. 738 Copenhagen. Luxembourg: Publications Office of the European Union 

2016 report, EEA Report No 34/2016. Copenhagen. Luxembourg: Publications Office of the European Union

European Environment Agency (EEA) (2017) Air quality in Europe - 2017 report. EEA Report No 13/2017. Copenhagen. Luxembourg: Publications Office of the European Union

743 Eurostat 2015. Just over $40 \%$ of the EU population lives in cities - Eurostat news release 172/2015, Eurostat

744 Franke J, Hellsten A, Schlünzen H, Carissimo B (2007) Best practice guideline for the CFD simulation of 745 flows in the urban environment COST Action 732, quality assurance and improvement of microscale 746 meteorological models, COST Office, p. 51

747 Fuzzi S, Baltensperger U, Carslaw K, Decesari S, Denier Van Der Gon H, Facchini M, Fowler D, Koren I, 748 Langford B, Lohmann U (2015). Particulate matter, air quality and climate: lessons learned and future needs. 749 Atmos Chem Phys 15: 8217-8299. https://doi.org/10.5194/acp-15-8217-2015

750 Gama C, Monteiro A, Pio C, Miranda A.I, Baldasano J, Tchepel O (2018). Temporal patterns and trends of particulate matter over Portugal: a long-term analysis of background concentrations. Air Qual Atmos Health 11: 397-407. https://doi.org/10.1007/s11869-018-0546-8

Karvosenoja N, Kangas L, Kupiainen K, Kukkonen J, Karppinen A, Sofiev M, Tainio M, Paunu V-V, Ahtoniemi P, Tuomisto JT (2011). Integrated modeling assessments of the population exposure in Finland to primary PM2. 5 from traffic and domestic wood combustion on the resolutions of 1 and $10 \mathrm{~km}$. Air Qual Atmos Health 4: 179-188. https://doi.org/10.1007/s11869-010-0100-9

Lateb M, Meroney R, Yataghene M, Fellouah H, Saleh F, Boufadel (2015) On the use of numerical modelling for near-field pollutant dispersion in urban environments - A review. Environ Pollut 208: 271-283. https://doi.org/10.1016/i.envpol.2015.07.039

Lee R, Naesslund E (1998) Lagrangian stochastic particle model simulations of turbulent dispersion around buildings. Atmos Environ 32: 665-672. https://doi.org/10.1016/S1352-2310(97)00313-0

Miranda A, Silveira C, Ferreira J, Monteiro A, Lopes D, Relvas H, Borrego C, Roebeling P (2015) Current air quality plans in Europe designed to support air quality management policies. Atmos Pollut Res 6: 434443. https://doi.org/10.5094/APR.2015.048

Misra A, Roorda MJ, MacLean HL (2013) An integrated modelling approach to estimate urban traffic emissions. Atmos Environ 73:81-91. https://doi.org/10.1016/j.atmosenv.2013.03.013

Moreno T, Lavin J, Querol X, Alastuey A, Viana M, Gibbons W (2009). Controls on hourly variations in urban background air pollutant concentrations. Atmos Environ 43: 4178-4186. https://doi.org/10.1016/i.atmosenv.2009.05.041

Eicker MO, Zah R, Triviño R, Hurni H (2008) Spatial accuracy of a simplified disaggregation method for traffic emissions applied in seven mid-sized Chilean cities. Atmos Environ 42: 1491-1502. https://doi.org/10.1016/i.atmosenv.2007.10.079

773 Palacios J (1999) Understanding and quantifying motor vehicle emissions with vehicle specific power and

TILDAS remote sensing. Department of Mechanical Engineering. Massachusetts Institute of Technology, Cambridge, Massachusett

776 Palacios M, Martín F, Cabral H (2001) Methodologies for estimating disaggregated anthropogenic emissions-application to a coastal Mediterranean region of Spain. J Air Waste Manag Assoc 51: 642-657. https://doi.org/10.1080/10473289.2001.10464305

779 Rafael S, Vicente B, Rodrigues V, Miranda A.I, Borrego C, Lopes M (2018) Impacts of green infrastructures 780 on aerodynamic flow and air quality in Porto's urban area. Atmos Environ 190: 317-330. 781 https://doi.org/10.1016/j.atmosenv.2018.07.044

782 Richards K, Schatzmann M, Leitl B (2006) A wind tunnel investigation of thermal effects within the vicinity of 
Richards PJ, Hoxey R (1993). Appropriate boundary conditions for computational wind engineering models using the k- $\varepsilon$ turbulence model. J Wind Eng Ind Aerod 46-47: 145-153

Rodrigues V, Rafael S, Sorte S, Coelho S, Relvas H, Vicente B, Leitão J, Lopes M, Miranda Al, Borrego C (2018) Adaptation to Climate Change at Local Scale: A CFD Study in Porto Urban Area. In: Computational Fluid Dynamics-Basic Instruments and Applications in Science. InTech, 22: 164-186. 789 https://10.5772/intechopen.72972

790 Smit R, Brown A, Chan Y (2008) Do air pollution emissions and fuel consumption models for roadways include the effects of congestion in the roadway traffic flow?. Environ Modell Softw 23: 1262-1270. https://doi.org/10.1016/j.envsoft.2008.03.001

793 Taghavi M, Cautenet S, Arteta J (2005) Impact of a highly detailed emission inventory on modeling accuracy.

794 Atmos Res 74: 65-88. https://doi.org/10.1016/i.atmosres.2004.06.007

Tchepel O, Dias D, Ferreira J, Tavares R, Isabel Miranda A, Borrego C (2012) Emission modelling of hazardous air pollutants from road transport at urban scale. Transport 27: 299-306. https://doi.org/10.3846/16484142.2012.720277

Thunis P, Miranda A, Baldasano J, Blond N, Douros J, Graff A, Janssen S, Juda-Rezler K, Karvosenoja N, Maffeis $G$ (2016) Overview of current regional and local scale air quality modelling practices: Assessment and planning tools in the EU. Environ Sci Policy 65: 13-21. https://doi.org/10.1016/j.envsci.2016.03.013

801 Tominaga $\mathrm{Y}$, Stathopoulos T (2013) CFD simulation of near-field pollutant dispersion in the urban 802 environment: A review of current modeling techniques. Atmos Environ 79: 716-730. 803 https://doi.org/10.1016/j.atmosenv.2013.07.028

804 URL1. European Environment Agency. Portugal - air pollution country fact sheet 2017. Available from: 805 https://www.eea.europa.eu/themes/air/country-fact-sheets/portugal. Accessed June 2018

USEPA (United States Environmental Protection Agency). (2002). Methodology for developing modal emission rates for EPA's multi-scale motor vehicle \& equipment emission system. Prepared by North Carolina State University. EPA 420. Ann Arbor. Michigan

809 Valente J, Pimentel C, Tavares R, Ferreira J, Borrego C, Carreiro-Martins P, Caires I, Neuparth N, Lopes M 810 (2014) Individual exposure to air pollutants in a Portuguese urban industrialized area. J Toxicol Env Health 811 A 77: 888-899. https://doi.org/10.1080/15287394.2014.910159

812 Viana M, Reche C, Amato F, Alastuey A, Querol X, Moreno T, Lucarelli F, Nava S, Calzolai G, Chiari M 813 (2013) Evidence of biomass burning aerosols in the Barcelona urban environment during winter time. 814 Atmosc Environ 72: 81-88. https://doi.org/10.1016/j.atmosenv.2013.02.031

815 Waked A, Favez O, Alleman L, Piot C, Petit J-E, Delaunay T, Verlinden E, Golly B, Besombes J-L, Jaffrezo $816 \mathrm{~J}-\mathrm{L}$ (2014) Source apportionment of PM 10 in a north-western Europe regional urban background site (Lens, 817 France) using positive matrix factorization and including primary biogenic emissions. Atmos Chem Phys14: 818 3325-3346. https://doi.org/10.5194/acp-14-3325-2014 